\title{
Sequential Therapy in Metastatic Renal Cell Carcinoma
}

\author{
Bradford R. Hirsch, John M. Burke, Manish Agrawal, Ralph J. Hauke, \\ Thomas E. Hutson, Gury Doshi, Mark T. Fleming, Nicholas J. Vogelzang
}

US Oncology Research, Houston, TX, USA

\begin{abstract}
The treatment of metastatic renal cell carcinoma (mRCC) has changed dramatically in the past decade. As the number of available agents, and related volume of research, has grown, it is increasingly complex to know how to optimally treat patients. The authors are practicing medical oncologists at the US Oncology Network, the largest community-based network of oncology providers in the country, and represent the leadership of the Network's Genitourinary Research Committee. We outline our thought process in approaching sequential therapy of $\mathrm{mRCC}$ and the use of real-world data to inform our approach. We also highlight the evolving literature that will impact practicing oncologists in the near future.
\end{abstract}

Keywords: kidney cancer; renal cell carcinoma; sequential therapy

Received: 29 December 2015; Accepted after revision: 22 February 2016; Published: 05 April 2016.

Author for correspondence: Bradford Hirsch, MD, 7777 Forest Lane, Suite D-400, Dallas, TX 75230. Email: Bradford.Hirsch@USOncology.com

How to cite: Hirsch BR, Burke JM, Agrawal M, Hauke RJ, Hutson TE, Doshi G, et al. Sequential therapy in metastatic renal cell carcinoma. J Kidney Cancer VHL 2016;3(1):23-35. Doi: http://dx.doi.org/10.15586/jkcvhl.2016.46

Copyright: The Authors.

License: This open access article is licensed under Creative Commons Attribution 4.0 International (CC BY 4.0). http://creativecommons.org/licenses/by/4.0

\section{Introduction}

The treatment of metastatic renal cell carcinoma (mRCC) has changed dramatically in the past decade. Between 2005 and 2012, six new therapies were approved for patients with metastatic disease, in addition to the older therapies of interferon and high-dose interleukin-2 (IL-2) (1). Furthermore, the introduction of new agents is not slowing. In September 2015, two landmark articles on nivolumab and cabozantanib in the New England Journal of Medicine advanced the field further $(2,3)$. Although the new therapies improve outcomes of patients with metastatic disease, there remain as many questions as answers about how best to incorporate the options into treatment algorithms for patients, creating a challenge for practicing oncologists.

To keep up with all of the literature is a daunting task. Guidelines published by groups such as the National Comprehensive Cancer Network (NCCN) help to guide 
treatment selection (4), yet often the multitude of choices can leave a practitioner uncertain as to which agent to select for a patient. There are also alternative guidelines such as those released by the European Association of Urology and the European Society for Medical Oncology (ESMO) $(5,6)$. As an example, the most recent NCCN guidelines list six therapeutic options for the first-line treatment of mRCC-sunitinib (Sutent, Pfizer), temsirolimus (Torisel, Pfizer), bevacizumab (Avastin, Roche/Genentech), interferon, pazopanib (Votrient, Novartis), high-dose IL-2, and sorafenib (Nexavar, Bayer)-as well as clinical trials and best supportive care. Other guidelines, such as those released in 2014 by ESMO, refer to stronger evidence for some, but are still quite inclusive. Despite the overlap in some of the classes of agents among these options, there is variability in their toxicity and efficacy profiles, so they are not readily interchangeable. Choice of second-line therapy and beyond becomes complex as many agents are available, including axitinib (Inlyta, Pfizer), everolimus (Afinitor, Novartis), sorafenib (Nexavar, Bayer), and nivolumab (Opdivo, Bristol-Meyers Squibb). To further complicate the picture, patients often become sicker as the disease progresses, forcing physicians to incorporate other considerations such as performance status, comorbidities, and preferences regarding end-of-life care into decisions about treatment options; in fact, evidence suggests that only about $50 \%$ of patients in the United States receive second-line therapy, as opposed to best supportive care (7). Italian analyses similarly showed that approximately 50\% of patients received second-line therapy, and only $13 \%$ of patients received third-line therapy $(8,9)$.

The authors are practicing medical oncologists at the US Oncology Network (USON), the largest community-based network of oncology providers in the country, who treat relatively high volumes of mRCC patients as members of the Genitourinary Research Committee. Herein, we outline our thought process in approaching sequential therapy of mRCC. The discussion represents our present approach and provides a framework upon which new agents and evidence need to be incorporated as they are introduced over the next months and years. Our experience is further advanced by the "real-world data" analyses that occur within the USON, leveraging the data generated by our treatments to provide new insights into how agents perform in routine clinical care. Such real-world data are critically important in order to demonstrate the external validity of the trial data upon which the guidelines are based.

\section{Standard of care in the first-line therapy}

Although there are six treatments listed as first-line options as per the $\mathrm{NCCN}$ guidelines, treatment selection becomes more manageable once patients are stratified according to risk category. We recommend risk stratification of patients according to the Memorial Sloan Kettering Cancer Center (MSKCC) criteria (10). As shown in Table $\mathbf{1}$, patients were categorized by five criteria into risk groups: good-risk $(0$ risk factors $)$, intermediate-risk (1-2), or poor-risk $(\geq 3)$. The Heng criteria were published following the introduction of subsequent agents and can alternatively be used for risk stratification (11). Both frameworks have significant prognostic implications with differences in the median overall survival (OS) in the original MSKCC trial of 19.9 months in the good-risk group compared with 3.9 months in the poor-risk group. In the Heng analysis (post introduction of newer agents), median OS was not reached in the good-risk group, was 27 months in the intermediate-risk group, and was 8.8 months in the poor-risk group. Neither is ideal because they do not fully account for the present era of targeted agents; however, they remain widely used due to their simplicity and the lack of alternative, validated tools. Based on this stratification, patients may be taken down different first- and second-line treatment pathways as shown in Figure 1. We outline the logic behind these treatment considerations subsequently.

Good-risk patients: role of IL-2

For patients who are young, otherwise healthy, and wish to be maximally aggressive, high-dose IL-2 can be considered. In one study, treatment with 
Table 1. Memorial Sloan Kettering Cancer Center (MSKCC) (10) and Heng risk (11) stratification

\begin{tabular}{|l|l|l|l|}
\hline Variables & Cutoff & MSKCC & Heng \\
\hline Karnofsky performance status & $<80 \%$ & $\mathrm{X}$ & $\mathrm{X}$ \\
\hline Hemoglobin & $<\mathrm{ULN}$ & $\mathrm{X}$ & $\mathrm{X}$ \\
\hline Calcium & $>10$ & $\mathrm{X}$ & $\mathrm{X}$ \\
\hline Time from diagnosis to treatment & $<1$ year & $\mathrm{X}$ & $\mathrm{X}$ \\
\hline LDH & $>1.5 \times$ ULN & $\mathrm{X}$ & \\
\hline Platelet count & $>$ ULN & & $\mathrm{X}$ \\
\hline Neutrophil count & $>$ ULN & & $\mathrm{X}$ \\
\hline
\end{tabular}

ULN: upper limit of normal.

Risk groups are defined as 0 risk factors $=$ favorable, $1-2$ risk factors $=$ intermediate, and $>2$ risk factors $=$ poor.

high-dose IL-2 achieved objective responses in $20 \%$ of patients, with complete responses (CRs) in 9\% (12). To date, no other agent approved in the treatment of mRCC has achieved similar $\mathrm{CR}$ results. The toxicity and intensity of treatment are quite high. Dave deBronkart (e-Patient Dave) gives talks about how his disease was cured by his search of the Internet, identification of IL-2 as an option, and active pursuit of it after his physicians failed to inform him about its availability (13). Patients should be able to similarly weigh the pros and cons of the various treatment options. However, as discussed subsequently, few receive the agent in practice.

Intermediate-risk patients: role of sunitinib us pazopanib

About half of patients with $\mathrm{mRCC}$ fall into the intermediate-risk category (10). Not taking into account clinical trials, the choice presently is largely between pazopanib and sunitinib for this cohort for the reasons outlined in the "other considerations" section. For these two agents, the landmark trials demonstrated an OS benefit for each agent, as shown in Table 2; however, the results cannot be clearly extrapolated to demonstrate a "preferred" agent. Two subsequent studies have informed care. The first is the COMPARZ (Pazopanib vs sunitinib in the treatment of locally advanced and/or metastatic renal cell carcinoma) trial (14). In this trial, 1,110 patients with clear cell mRCC were randomized to pazopanib at 800 $\mathrm{mg}$ daily or sunitinib at $50 \mathrm{mg}$ on a 4-week on and a 2-week off schedule. The primary endpoint was progression-free survival (PFS), and the trial was powered for non-inferiority, and not for superiority. The hazard ratio (HR) was 1.05 with a 95\% confidence interval (CI) of 0.90 to 1.22 . The upper bound of the CI for non-inferiority was predetermined at 1.25 , so the trial just met the goal of noninferiority. There continues to be controversy related to the study design. For instance, true non-inferiority would require both the intention-to-treat and per-protocol approaches to meet the predetermined cut off; however, the CI for the per-protocol had an upper bound of 1.25 , equaling the prespecified cutoff. Despite these limitations, the patient experiences favored pazopanib in terms of fatigue (63\% with sunitinib vs $55 \%$ with pazopanib), hand-foot syndrome $(50 \%$ vs $29 \%)$, and thrombocytopenia (78\% vs $41 \%)$. Eleven of 14 Health Related Quality of Life (HRQoL) domains also favored pazopanib. Of note, liver function abnormalities were higher with pazopanib (60\% vs 43\%). The conclusion of the authors was that pazopanib and sunitinib have similar efficacy as first-line therapy, but the best available toxicity information favors pazopanib.

The second trial of relevance is PISCES (Patient preference study of pazopanib vs sunitinib in advanced or metastatic kidney cancer) (15). A total of 169 patients were randomized to either pazopanib or sunitinib per the dosing approaches outlined above. After 10 weeks on therapy, there was a 2week washout period, and patients were then switched to the other agent for 10 weeks of further therapy. The primary endpoint was patient preference between agents. Seventy percent preferred pazopanib, 22\% sunitinib, and $8 \%$ expressed no preference. The main drivers were fatigue and overall quality of life (QOL). The conclusion of the authors was that pazopanib was preferred by patients. 


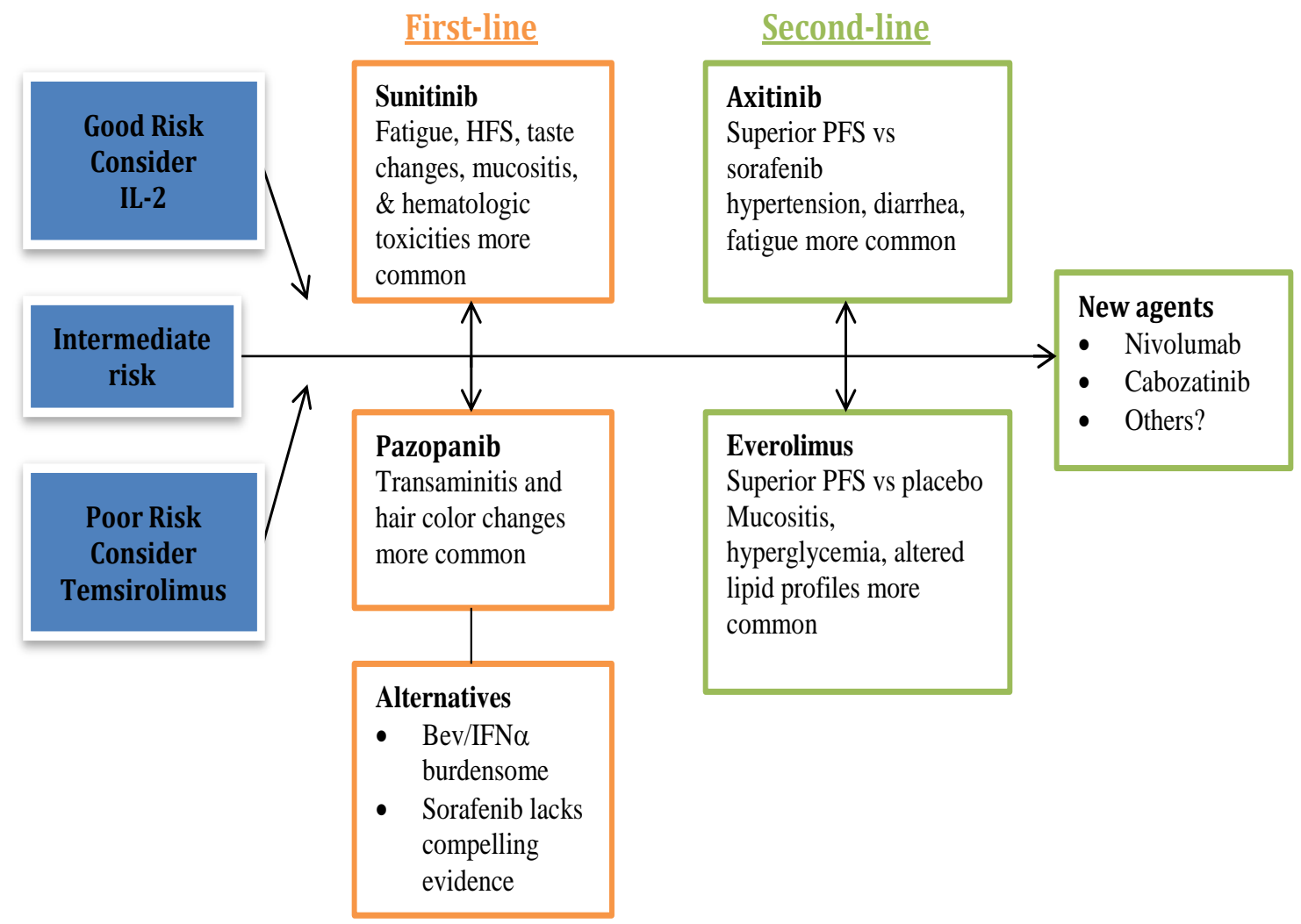

Figure 1. Treatment decision tree for first- and second-line therapy in metastatic renal cell carcinoma based on available and evolving evidence. Bev: bevacizumab; HFS: hand foot syndrome; IFNa: interferon alfa; PFS: progression free survival.

As a result of these two trials, both funded by GlaxoSmithKline, there appears to be a preference for pazopanib in the community and in many academic centers. However, when interpreting the results of COMPARZ and PISCES, one must take into account a few important considerations. First, although not in the product label, many clinicians have subsequently switched from a 4-week on and a 2-week off schedule for sunitinib to

Table 2. Results of landmark(s) trials of FDA-approved agents in the treatment of metastatic renal cell carcinoma in first- and second-line

\begin{tabular}{|c|c|c|c|c|}
\hline Agents & Comparator & $\begin{array}{l}\text { Study year for } \\
\text { OS results }\end{array}$ & $\begin{array}{l}\text { Median PFS, } \\
\text { mo }\end{array}$ & Median OS, mo \\
\hline \multicolumn{5}{|l|}{ First-line } \\
\hline Pazopanib & Placebo & $2013(45)$ & 11.1 vs $2.8^{*}$ & 22.9 vs 20.5 \\
\hline $\mathrm{Bev}+\mathrm{IFN}-\mathrm{a}$ & IFN-a & $2010(21,24)$ & $\begin{array}{l}10.2 \text { vs } 5.4^{*} \\
8.5 \text { vs } 5.2^{*}\end{array}$ & $\begin{array}{l}23.3 \text { vs } 21.3 \\
18.3 \text { vs } 17.4\end{array}$ \\
\hline Sorafenib & IFN-a & 2009 (26) & 5.7 vs 5.6 & Not reported \\
\hline Sunitinib & IFN-a & 2009 (18) & 11 vs $5^{*}$ & 26.4 vs 21.8 \\
\hline Temsirolimus** & IFN-a & 2007 (17) & 5.5 vs 3.1 & 10.9 vs $7.3^{*}$ \\
\hline \multicolumn{5}{|l|}{ Second-line } \\
\hline Nivolumab & Everolimus & $2015(2)$ & 4.6 vs 4.4 & 25.0 vs $19.6^{*}$ \\
\hline Axitinib & Sorafenib & 2011 (32) & 6.7 vs $4.7^{*}$ & \\
\hline Everolimus & Placebo & 2010 (35) & 4.9 vs $1.9^{*}$ & 14.8 vs 14.4 \\
\hline
\end{tabular}

*Statistically significant.

**For poor-risk patients by MSKCC criteria.

Bev: bevacizumab; HD: high dose; IFN-a: interferon alfa; mo: month; OS: overall survival; PFS: progression-free survival. 
a 2-week on and a 1-week off schedule. Early trials have shown improved tolerability with no impact on outcomes (16). It is unknown what impact this change in schedule would have on HRQoL patients shown in the COMPARZ and PISCES trials.

Another key is that the timing of assessments in the trials may have biased in favor of pazopanib by assessing tolerability at the end of the 4 weeks on therapy with sunitinib. This represents the time of maximum toxicity. If taken after the two off weeks, the HRQoL may have been better in the sunitinib arm. Despite these concerns, the data from COMPARZ and PISCES represent the best available information with which to choose between the agents.

\section{Poor-risk patients: role of temsirolimus}

In the same way that IL-2 has a specific indication in the particularly fit patient, temsirolimus has a niche in poor-risk patients. In the phase III trial of the agent, 626 treatment naïve patients were given weekly temsirolimus, temsirolimus plus interferon-alfa, or interferon-alfa alone (17). Monotherapy with temsirolimus was superior to interferon-alfa in terms of OS (10.9 vs 7.3 months, HR, 0.83 [95\% CI, 0.58-0.92]). The combination arm was similar to interferon-alfa monotherapy at 8.4 months. A similar superiority for temsirolimus monotherapy was seen in PFS.

No other agents have data specifically supporting their use in the poor-risk space. For example, the pivotal trials for sunitinib and pazopanib included very few poor-risk patients at only $6 \%$ and $3 \%$, respectively $(18,19)$. The subset was, therefore, not large enough to provide compelling data as to their role. There is an ongoing phase II trial comparing temsirolimus with pazopanib, which will further define the role of temsirolimus, as will ongoing realworld analyses (20).

\section{Other considerations}

- Other approved regimens: Although bevacizumab plus interferon-alfa has a category 1 indication in the $\mathrm{NCCN}$ guidelines based on the AVOREN and CALGB 90206 (Cancer and Leukemia Group B 90206) results, no trial has demonstrated an OS benefit for the addition of bevacizumab. We do not favor this regimen because of the toxicities of interferon, the need for frequent subcutaneous and intravenous administration of the agents, and the availability of the other orally administered agents discussed above (21-24). Sorafenib does not have a category 1 indication because TARGET (Treatment Approaches in Renal Cancer Global Evaluation Trial) did not show an OS benefit, and the previous phase II did not show a PFS advantage when compared to interferon-alfa (25-27).

- Combinations of agents: Numerous trials have looked at combinations of agents, hoping to demonstrate synergistic effects and tolerable side effects, but they have not been shown to be beneficial. An example is the BEST (BEvacizumab, Sorafenib, and Temsirolimus) trial that compared bevacizumab, bevacizumab plus temsirolimus, bevacizumab plus sorafenib, and sorafenib plus temsirolimus (28). No combination arm showed superiority with a PFS of 8.7 months for monotherapy vs $7.3,11.3$, and 7.7 months for the other arms, respectively. An exception to this lack of benefit to combination therapies can be seen with the recent evidence showing benefit for the combination of lenvatinib and everolimus in the second-line as presented subsequently.

\section{Real-world practice patterns}

The use of data generated in clinical practice to inform treatment considerations has not been fully realized. A recent article compared patients included in the pivotal clinical trials with those treated with sunitinib, sorafenib, pazopanib, and temsirolimus in the community. The "realworld" cohort were part of a joint academiccommunity registry (29). Overall, 39\% of the registry patients would not have met the inclusion and/or exclusion criteria for the relevant pivotal trial used to approve the drug that they received. As an example, among the 438 community patients, those who received tyrosine kinase inhibitors (TKIs) were more likely to have poor-risk disease $(7.4 \%$ vs $2.9 \%, P<0.001)$ and less likely to have favorable disease $(30.1 \%$ vs 
$43.8 \%, P<0.001)$ when compared with those in the trials. Those treated with temsirolimus were less likely to have poor-risk disease (10.2\% vs $69.4 \%$ ) when compared with those in the trial, despite poor risk being the indication for the use of the agent.

These findings beg the question of whether those patients treated in the community have similar outcomes and toxicity profiles with those who participate in the clinical trials used to approve a given agent. An abstract presented at the ASCO Genitourinary Meeting in January 2016 described outcomes of USON patients treated with pazopanib or sunitinib in the first-line (30). Median PFS was 9.3 months with pazopanib and 8.3 months with sunitinib when compared with 11 and 11.1 months in the pivotal trials, as shown in Table 2. Median OS was also similar between the two agents at 22.3 and 26.3 months in the USON retrospective cohorts, respectively, when compared with 22.9 and 26.4 months in the pivotal trials. These results are reassuring that the outcomes are not dramatically different in our experience overall, or by agent. In the USON retrospective series, adverse events (any grade), including anorexia, skin toxicity, and stomatitis, were significantly less common among pazopanib-treated patients $(P<0.05)$, whereas diarrhea, hypertension, nausea, and vomiting were significantly less common with sunitinib $(P<0.05)$. Patients treated with sunitinib also appeared to have higher incidence of headache and pain in an extremity although the difference was not statistically significant.

A similar analysis of the communityacademic registry as to the rate of adverse events is instructive in showing the tolerability of these agents in practice (7). Of the 466 patients captured in the realworld registry, 57\% experienced fatigue that was severe enough to lead to documentation in the chart, 40\% vomiting, $34 \%$ diarrhea, 33\% asthenia, and $21 \%$ mucosal inflammation. This demonstrates the frequency of difficulties with tolerance in this patient population. When looking at sunitinib, only $46 \%$ of patients remained on full-dose therapy (50 $\mathrm{mg}$ ) by the end of therapy. Sixteen percent were on a dose of $25 \mathrm{mg}$ or below, calling into question the effectiveness of the therapy being provided in these instances.
In order to optimally manage these patients, we must ensure that effectiveness and tolerability in practice are documented, and disseminated to the treatment community. A recent survey of medical oncology experts representing 11 cancer centers of excellence from around the world assessed variations in treatment approaches (31). The authors found great heterogeneity in decision criteria and were struck by how "differently the available data are interpreted and implemented by experts." This shows the difficulty in applying the available results from clinical trials to patients in the real world.

\section{US Oncology Network approach}

We recommend either pazopanib or sunitinib as first-line options in the treatment of $\mathrm{mRCC}$. If sunitinib is used, we often use a dose and schedule of $50 \mathrm{mg}$ daily for 2 weeks on and 1 week off based on the data suggesting better tolerability although we acknowledge that the quality of the data is not of the highest level. Although temsirolimus is certainly reasonable in poor-risk patients, the authors are nearly evenly split on its use in practice as the preferred agent. Four use it regularly, one uses it occasionally, and the remaining three do not use it, instead giving pazopanib or sunitinib. IL-2 is rarely used as well. Because of the toxicity and need for hospitalization, we recommend administration only in highvolume centers with considerable experience and in otherwise healthy, younger patients. Among the authors, all consider administering it, yet some have never given it and others do so quite rarely. With the introduction of immunotherapies, the pendulum is likely to swing yet further away.

The hope is that, as real-world data are increasingly refined, they could be used to simplify the treatment algorithm yet further based on the balance of relative value and the validation of findings such as the rate of CR with IL-2 and preferential utility of temsirolimus in the identified niche. To take this one step further, the hope is to personalize treatments for a given patient based on their unique characteristics such as age, comorbidities, and goals of care.

\section{Standard of care in the second-line}

Second-line therapy is changing. Per the NCCN guidelines, if patients receive either 
IL-2 or temsirolimus in the first-line, they should receive either pazopanib or sunitinib in the second-line. However, for those who receive either pazopanib or sunitinib in the first-line, the choice in the second-line is less straightforward. There is evidence to support both a mammalian target of rapamycin (mTOR) inhibitor and a TKI. The preferred agent has not been clearly demonstrated.

\section{Axitinib vs everolimus}

Axitinib was approved based on the AXIS (Axitinib versus Sorafenib in Advanced Rena Cell Carcinoma) trial in which 723 patients were randomized to axitinib or sorafenib (32). All had received one prior therapy. The median PFS for axitinib was 8.3 vs 5.7 months with sorafenib (HR, $0.665,95 \%$ CI, 0.544-0.812). There was no difference in OS. The most common side effects with axitinib were diarrhea, hypertension, and fatigue. These findings established axitinib as the preferred choice over sorafenib in the second-line setting.

Everolimus was approved based on the RECORD-1 (Renal Cell Cancer Treatment with Oral RAD001 given daily) results in which it was compared to placebo (33-35). In the trial, 410 patients were assigned 2:1 to everolimus or placebo. All had received at least one, if not two, prior treatments with sunitinib and/or sorafenib. The median PFS for everolimus was 4.0 vs 1.9 months with placebo. No OS impact was seen in the trial although the crossover rate was over $90 \%$. It was also clear that there was benefit for everolimus as a third-line agent. The most common adverse events with everolimus included stomatitis, rash, and fatigue. Pneumonitis occurred in $8 \%$ of patients.

Because there was not a head-to-head comparison, it is difficult to decide which agent is preferred to date in the second-line. Is a TKI-mTOR strategy preferable to TKI-TKI? The INTORSECT (Investigating Torisel as Second-Line Therapy) trial is somewhat instructive. In this trial of patients previously treated with sunitinib, the PFS results were similar whether a patient was treated with mTOR or TKI in the second-line (4.3 vs 3.9 months, HR, 0.87 [95\% CI, 0.71-1.07]); however, OS was inferior in the TKI-mTOR group at 12.3 vs 16.6 months (HR, 1.31 [95\% CI, 1.05-163]). The greatest benefit of the TKI-
TKI approach was seen in patients who had over 6 months of response to sunitinib in the first-line. A factor in favor of axitinib over everolimus is its ability to produce responses: axitinib produces a response rate of about $20 \%$ in the second-line setting, whereas the response rate of everolimus is $<5 \%$.

Despite the three large trials discussed (RECORD-1, AXIS, and INTORSECT), there is not a clear treatment of choice in the secondline to date between axitinib and everolimus. INTORSECT looked at temsirolimus, which is not the agent used in the second-line, RECORD-1 compared the agent with placebo, and no trials showed an OS benefit. Although the details are indeed thought provoking, they require assessment in the real world, if not a prospective trial, in order to answer the question of what agent to use. An example of such an analysis can be seen in an article that is presently undergoing peer review, in which the real-world experiences with axitinib and everolimus were compared (36). The results showed that PFS did not differ significantly between everolimus and axitinib (HR, 1.16 [95\% CI, 0.73-1.82]). However, axitinib was associated with $17 \%$ higher drug costs per month of PFS at $\$ 12,467$ vs $\$ 10,637(P<0.001)$. This is an example of how real-world data can be used to advance treatment paradigms.

Evolving second-line literature: roles of nivolumab, cabozantinib, and lenvatinib

Nivolumab is a monoclonal antibody directed at programmed death (PD)-1. Inhibition of PD- 1 by nivolumab drives T-cell immunity and has been successful in treating nonsmall-cell lung cancer and melanoma among other cancer types. In a phase III trial, 821 patients with mRCC with a clear cell component were randomly assigned to receive either nivolumab or everolimus and treated until progression or unacceptable toxicity (2). Nivolumab was administered at a dose of $3 \mathrm{mg} / \mathrm{kg}$ intravenously every 2 weeks, and everolimus was administered at a dose of $10 \mathrm{mg}$ orally daily. PFS was not significantly different at 4.6 months with nivolumab vs 4.4 months with everolimus; however, OS was 25.0 and 19.6 months (HR, 0.73 [95\% CI, 0.57-0.93]), respectively. Overall response rate (ORR) was $25 \%$ with nivolumab vs $5 \%$ with everolimus, with similar $\mathrm{CR}$ rates of $1 \%$ and $<1 \%$. Responses 
were consistent across subgroups of MSKCC risk and PD-L1 status. The rate of grade 3 or 4 toxicity was preferable for nivolumab at $19 \%$ vs $37 \%$ with everolimus. This trial demonstrated the efficacy of nivolumab in treating $\mathrm{mRCC}$ and resulted in the Food and Drug Administration (FDA) approval on November 23, 2015. We predict that nivolumab will be widely used in the treatment of patients with $\mathrm{mRCC}$ after failure of a TKI. The role of immune checkpoint inhibitors in the first-line setting is being actively investigated in clinical trials.

Although checkpoint inhibitors garner much of the attention, other promising results from agents are being studied. Cabozantinib (Cometriq, Exelixis) is an oral, small-molecule TKI, a different target profile (37). In the METEOR trial (A Trial of Cabozatinib (XL184) vs Evereolimus in Subjects with Metastatic Renal Cell Carcinoma), 658 patients with metastatic kidney cancer and a clear cell component were randomly assigned to either cabozantinib at $60 \mathrm{mg}$ orally daily or everolimus at $10 \mathrm{mg}$ orally daily (3). Patients had to have received at least one prior TKI. The median PFS was 7.4 with cabozantinib vs 3.8 months with everolimus (HR, 0.58 [95\% CI, 0.45-0.75]). The ORR was $21 \%$ vs $5 \%$ $(P<0.001)$. Although there was a trend in favor of improved OS with cabozantinib (HR, 0.67 [95\% CI, 0.51-0.89]), it did not meet the predefined boundary for the interim analysis. The data will continue to mature. The main concern is that $60 \%$ of patients in the cabozatinib arm required dose reductions vs $25 \%$ of patients in the everolimus arm. The discontinuation rates were similar at $9 \%$ and $10 \%$, respectively. The conclusion of this study is that, as a therapy for RCC refractory to prior TKI therapy, cabozantinib improves PFS when compared with everolimus. The response rate was similar to axitinib. Whether cabozantinib offers advantages over axitinib, the TKI already FDA approved in the same setting, is unclear. Cabozantinib has not been FDA approved for RCC (although it is approved for medullary thyroid cancer) at the time of this writing.

Finally, a phase II trial was published in The Lancet on October 15, 2015, that assessed lenvatinib, everolimus, and lenvatinib/ everolimus in the second-line among 153 mRCC patients (38). Mouse models have shown that the fibroblast growth factor (FGF) may be a mechanism of resistance to TKIs. Lenvatinib has a unique mechanism of action in that it is a potent inhibitor of both VEGF and FGF receptors, potentially providing benefit despite progression on a prior TKI. Lenvatinib use in combination with an mTOR inhibitor showed yet greater activity in these models. The phase III study showed that the combination significantly prolonged PFS when compared with everolimus alone at 14.6 vs 5.5 months (HR, 0.40 [95\% CI, 0.24$0.68]$ ) but not with lenvatinib alone at $14.6 \mathrm{vs}$ 7.4 months (HR, 0.66 [95\% CI, 0.30-1.1]). Grade 3 or 4 events occurred in $71 \%$ of those receiving combination therapy, $79 \%$ of lenvatinib-treated patients, and $50 \%$ of everolimus-treated patients. No survival data are yet available.

\section{Real-world practice patterns and the USON pathways}

Nivolumab is likely to become the new standard of care in the second-line based on the data showing a preferential toxicity profile, higher response rate, and 5.4-month improvement in OS. Axitinib is still a reasonable option after failure of a prior TKI; however, we predict that the novel mechanism of action of nivolumab, the proven survival advantage (which axitinib does not have), and the general excitement within the oncology community about checkpoint inhibitors will lead to the use of nivolumab. Axitinib may instead be used as third-line. If cabozantinib becomes approved by the FDA, it could also be used as a third-line treatment. Decisions will likely be based on cost, toxicity profile, patient preference, and results of published follow-up. An ongoing trial comparing cabozantinib with sunitinib in the first-line has completed accrual (39).

\section{Evolving literature and next steps}

We predict that there will be extensive study of combinations of agents such as nivolumab with sunitinib, pazopanib, or ipilimumab (40). Although combinations have proven difficult in RCC, the toxicity profile and response of nivolumab may make its use in combination a viable option.

Over the next few years, the role of checkpoint inhibitors will evolve further as other agents are approved, as has occurred with TKI and mTOR inhibitors, and as 
first-line trials read out. Combinations of checkpoint inhibitors and anti-angiogenic agents will continue to be studied although early trials have shown significant toxicity. A phase 1 trial looking at nivolumab with either sunitinib or pazopanib showed that $73 \%$ and $60 \%$ of patients experienced grade 3 or 4 toxicities, respectively (41). Dual checkpoint inhibition-such as combining a PD-1 antibody like nivolumab with an alternative immunotherapy-is being studied. Nivolumab with ipilimumab (Yervoy, Bristol Meyers Squibb) was first approved on October 1, 2015, for the treatment of metastatic melanoma. A similar trial in $\mathrm{mRCC}$ is ongoing (CheckMate 214). In metastatic melanoma, the combination improved PFS from 4.7 with ipilimumab alone to 8.9 months with the combination (42).

There are other classes of agents in the pipeline as well. An example is the promise of autologous dendritic cell immunotherapy. The ADAPT (Autologous Dendritic Cell Immunotherapy Plus Standard Treatment of Advanced Renal Cell Carcinoma) trial of autologous dendritic cell immunotherapy has completed enrollment of 450 patients as of July 2015 (43). The agent, AGS-003, is being given in conjunction with sunitinib in newly diagnosed patients to assess the effect of a combined approach of TKI and immunotherapy. Data from the phase III IMPRINT (IMA901 in Patients Receiving Sunitinib for Advanced/Metastatic Renal Cell Carcinoma) trial looking at IMA901, a vaccine in combination with sunitinib, were presented at the European Cancer Congress in late 2015 and did not meet the primary endpoint of an extension in OS (44).

Beyond the introduction of new agents, the utility of data and informatics to drive care is promising. Groups such as the USON are establishing systems and approaches that will leverage data from electronic health records, genomic analyses, and other systems to assess risk, improve understanding of the optimal role for specific agents, and provide clinical decision support to enable personalized recommendations. Real-world data could be used to update the analyses and help to further define the roles of available agents. It is likely that the output would be more nuanced and complex than prior approaches; however, it could be supported with available systems.

\section{Conclusions}

Although the mRCC treatment landscape can seem quite complex and overwhelming, the approach to treatment is relatively straightforward. Pazopanib and sunitinib represent the standard-of-care options we prefer for initial therapy in most patients with metastatic disease, with temsirolimus and IL-2 playing a role in limited situations. Nivolumab was recently approved by the FDA and will likely become the preferred second-line therapy. Axitinib is also reasonable to use in the second-line setting. Cabozantinib appears promising, but is not yet FDA approved. We suspect that axitinib and cabozantinib will begin to be used as third-line agents, with everolimus reserved for fourth-line. Sorafenib is also available, but its role at this point has become unclear. Finally, we encourage our patients to consider clinical trials, so that they may have access to the latest discoveries and contribute to finding a cure for kidney cancer.

\section{Conflicts of interest}

Hirsch: research funding-Pfizer, Bristol Meyers Squibb, Dendron, GlaxoSmithKline, Astellas, Sanofi; advisory board-Astellas, Pfizer, Hospira, Sandoz, Genentech; and stock/ownership interest-SignalPath Research, Flatiron Health. Hutson: research, speaker, advisory board/consultant: Pfizer, Novartis, Bayer, BMS, Eisai, Aveo. Burke: advisory boards-Gilead, Incyte, Millennium, Janssen Pfizer; travel-TG Therapeutics. Vogelzang: research funding from Pfizer, Novartis, Bayer, BMS, and Exelixis. Hauke, Doshi, Fleming, and Agrawal declare no potential conflict of interest with respect to research, authorship and/or publication of this article.

\section{References}

1. Centerwatch. Approved drugs by therapeutic area [Internet]. 2015 [cited 2015 June 22].

Available from:

http://www.centerwatch.com/drug-

information/fda-approvals/drug-

areas.aspx?AreaID $=12$ 
2. Motzer RJ, Escudier B, McDermott DF, George S, Hammers HJ, Srinivas S, et al. Nivolumab versus everolimus in advanced renal-cell carcinoma. $\mathrm{N}$ Engl $\mathrm{J}$ Med. 2015;373(19):1803-13.

http://dx.doi.org/10.1056/NEJMoa15106

65.

3. Choueiri TK, Escudier B, Powles T, Mainwaring PN, Rini BI, Donskov F, et al; METEOR Investigators. Cabozantinib versus everolimus in advanced renal-cell carcinoma. N Engl J Med. 2015;373:1814-23. http://dx.doi.org/10.1056/NEJMoa15100 $\underline{16}$.

4. National Comprehensive Cancer Network. NCCN Clinical Practice Guidelines in Oncology (NCCN Guidelines): Kidney Cancer. Washington, PA: NCCN; 2014.

5. European Association of Urology. Guidelins in Renal Cell Carcinoma. Arnheim, Netherlands: EAU; 2015.

6. Escudier B, Porta C, Schmidinger M, Algaba F, Patard JJ, Khoo V, et al; ESMO Guidelines Working Group. Renal cell carcinoma: ESMO Clinical Practice Guidelines for diagnosis, treatment and follow-up. Ann Oncol. 2014;25(suppl 3):iii49-56.

http://dx.doi.org/10.1093/annonc/mdu25 9.

7. Hirsch BR, Harrison MR, George DJ, Walker MS, Chen C, Korytowsky B, et al. Use of "Real-World" data to describe adverse events during the treatment of metastatic renal cell carcinoma in routine clinical practice. Med Oncol. 2014;31:156. http:/ /dx.doi.org/10.1007/s12032-0140156-8.

8. Iacovelli $R$, Carteni $G$, Sternberg $C N$, Milella M, Santoni M, Di Lorenzo G, et al. Clinical outcomes in patients receiving three lines of targeted therapy for metastatic renal cell carcinoma: results from a large patient cohort. Eur J Cancer. 2013;49(9):2134-42.

http://dx.doi.org/10.1016/j.ejca.2013.02. 032.

9. Levy A, Menard J, Albiges L, Loriot Y, Di Palma M, Fizazi K, et al. Second line treatment of metastatic renal cell carcinoma: The Institut Gustave Roussy experience with targeted therapies in 251 consecutive patients. Eur J Cancer. 2013;49(8):1898-1904.

http://dx.doi.org/10.1016/j.ejca.2013.02. $\underline{003}$.

10. Motzer RJ, Mazumdar M, Bacik J, Berg W, Amsterdam A, Ferrara J. Survival and prognostic stratification of 670 patients with advanced renal cell carcinoma. J Clin Oncol. 1999;17:2530-40.

11. Heng DY, Xie W, Regan MM, Warren MA, Golshayan AR, Sahi C, et al. Prognostic factors for overall survival in patients with metastatic renal cell carcinoma treated with vascular endothelial growth factor-targeted agents: results from a large, multicenter study. J Clin Oncol. 2009;27(34):5794-99.

http://dx.doi.org/10.1200/JCO.2008.21.4 809.

12. Klapper JA, Downey SG, Smith FO, Yang JC, Hughes MS, Kammula US, et al. High-dose interleukin-2 for the treatment of metastatic renal cell carcinoma: a retrospective analysis of response and survival in patients treated in the surgery branch at the National Cancer Institute between 1986 and 2006. Cancer. 2008;113(2):293-301.

http://dx.doi.org/10.1002/cncr.23552.

13. e-Patient Dave: A voice of patient engagement [Internet]. 2015 [cited 2015 June 22].

Available from:

http://www.epatientdave.com/.

14. Motzer RJ, McCann L, Deen K. Pazopanib versus sunitinib in renal cancer. N Engl J Med. 2013;369(20):1970. http://dx.doi.org/10.1056/NEJMc131179 $\underline{5}$.

15. Escudier B, Porta C, Bono P, Powles T, Eisen T, Sternberg CN, et al. Randomized, controlled, double-blind, cross-over trial assessing treatment preference for pazopanib versus sunitinib in patients with metastatic renal cell carcinoma: PISCES Study. J Clin Oncol. 2014;32(14):1412-8. http://dx.doi.org/10.1200/JCO.2013.50.8 $\underline{267}$ 
16. Kalra S, Rini BI, Jonasch E. Alternate sunitinib schedules in patients with metastatic renal cell carcinoma. Ann Oncol. 2015;26(7):1300-4.

http://dx.doi.org/10.1093/annonc/mdv030.

17. Hudes G, Carducci M, Tomczak P, Dutcher J, Figlin R, Kapoor A, et al; Global ARCC Trial. Temsirolimus, interferon alfa, or both for advanced renal-cell carcinoma. N Engl J Med. 2007;356:2271-81.

http://dx.doi.org/10.1056/NEJMoa066838.

18. Motzer RJ, Hutson TE, Tomczak $\mathrm{P}$, Michaelson MD, Bukowski RM, Oudard S, et al. Overall survival and updated results for sunitinib compared with interferon alfa in patients with metastatic renal cell carcinoma. J Clin Oncol. 2009;27(22): 3584-90.

http://dx.doi.org/10.1200/JCO.2008.20.1 293.

19. Sternberg CN, Davis ID, Mardiak J, Szczylik C, Lee E, Wagstaff J, et al. Pazopanib in locally advanced or metastatic renal cell carcinoma: results of a randomized phase III trial. J Clin Oncol. 2010;28:1061-8.

http://dx.doi.org/10.1200/JCO.2009.23.9 764.

20. Clinicaltrials.gov. Pazopanib versus temsirolimus in poor-risk clear cell renal cell carcinoma [Internet]. 2015 [cited 2015 November 22].

Available from:

http://www.clinicaltrials.gov/ct2/show/N CT01392183.

21. Escudier B, Bellmunt J, Négrier $\mathrm{S}$, Bajetta E, Melichar B, Bracarda S, et al. Phase III trial of bevacizumab plus interferon alfa-2a in patients with metastatic renal cell carcinoma (AVOREN): final analysis of overall survival. J Clin Oncol. 2010;28(13):2144-50.

http://dx.doi.org/10.1200/JCO.2009.26.7 849.

22. Escudier B, Pluzanska A, Koralewski P, Ravaud A, Bracarda S, Szczylik C, et al; AVOREN Trial Investigators. Bevacizumab plus interferon alfa-2a for treatment of metastatic renal cell carcinoma: a randomised, double-blind phase III trial. Lancet. 2007;370(9605):2103-11.
http://dx.doi.org/10.1016/S01406736(07)61904-7.

23. Rini BI, Halabi S, Rosenberg JE, Stadler WM, Vaena DA, Ou SS, et al. Bevacizumab plus interferon alfa compared with interferon alfa monotherapy in patients with metastatic renal cell carcinoma: CALGB 90206. J Clin Oncol. 2008;26:5422-8.

http://dx.doi.org/10.1200/JCO.2008.16.9 $\underline{847}$.

24. Rini BI, Halabi S, Rosenberg JE, Stadler WM, Vaena DA, Archer L, et al. Phase III trial of bevacizumab plus interferon alfa versus interferon alfa monotherapy in patients with metastatic renal cell carcinoma: final results of CALGB 90206. J Clin Oncol. 2010;28:2137-43.

http://dx.doi.org/10.1200/JCO.2009.26.5 $\underline{561 .}$.

25. Escudier B, Eisen $T$, Stadler WM, Szczylik C, Oudard S, Siebels M, et al; TARGET Study Group. Sorafenib in advanced clear-cell renal-cell carcinoma. N Engl J Med. 2007;356(2):125-34.

http://dx.doi.org/10.1056/NEJMoa06065 …

26. Escudier B, Eisen T, Stadler WM, Szczylik C, Oudard S, Staehler M, et al. Sorafenib for treatment of renal cell carcinoma: Final efficacy and safety results of the phase III treatment approaches in renal cancer global evaluation trial. J Clin Oncol. 2009;27(20):3312-8.

http://dx.doi.org/10.1200/JCO.2008.19.5 $\underline{511}$.

27. Escudier B, Szczylik C, Hutson TE, Demkow T, Staehler M, Rolland F, et al. Randomized phase II trial of first-line treatment with sorafenib versus interferon Alfa-2a in patients with metastatic renal cell carcinoma. J Clin Oncol. 2009;27: 1280-9.

http://dx.doi.org/10.1200/JCO.2008.19.3 342.

28. McDermott DF, Manola J, Pins M, et al. The BEST trial (E2804): a randomized phase II study of VEGF, RAF kinase, and mTOR combination targeted therapy (CTT) with bevacizumab (bev), sorafenib (sor), 
and temsirolimus (tem) in advanced renal cell carcinoma (RCC). J Clin Oncol [ASCO abstract 345]. 2013;31(suppl 6).

29. Mitchell AP, Harrison MR, Walker MS, George DJ, Abernethy AP, Hirsch BR. Clinical trial participants with metastatic renal cell carcinoma differ from patients treated in real-world practice. J Oncol Pract. 2015;11:491-7.

http://dx.doi.org/10.1200/JOP.2015.0049 $\underline{29}$.

30. Hirsch BR, Jiao X, Wilson T, Hackshaw MD, Jonasch E, Ghate S, et al. Compartive effectiveness of pazopaninb and sunitinib as first line therapy for patients with advanced/metastatic renal cell carcinoma in a US community oncology setting. J Clin Oncol 34, 2016(suppl 2S; abstr 567).

31. Rothermundt C, Bailey A, Cerbone L, Eisen T, Escudier B, Gillessen S, et al. Algorithms in the first-line treatment of metastatic clear cell renal cell carcinomaanalysis using diagnostic nodes. Oncologist. 2015;20(9):1028-35.

http://dx.doi.org/10.1634/theoncologist.2 $\underline{015-0145 .}$.

32. Rini BI, Escudier B, Tomczak P, Kaprin A, Szczylik C, Hutson TE, et al. Comparative effectiveness of axitinib versus sorafenib in advanced renal cell carcinoma (AXIS): a randomised phase 3 trial. Lancet. 2011;378(9807):1931-9.

http://dx.doi.org/10.1016/S01406736(11)61613-9.

33. Calvo E, Escudier B, Motzer RJ, Oudard S, Hutson TE, Porta C, et al. Everolimus in metastatic renal cell carcinoma: Subgroup analysis of patients with 1 or 2 previous vascular endothelial growth factor receptor-tyrosine kinase inhibitor therapies enrolled in the phase III RECORD-1 study. Eur J Cancer. 2012;48(3):333-9.

http://dx.doi.org/10.1016/j.ejca.2011.11. $\underline{027}$.

34. Motzer RJ, Escudier B, Oudard S, Hutson TE, Porta C, Bracarda S, et al; RECORD-1 Study Group. Efficacy of everolimus in advanced renal cell carcinoma: a double-blind, randomised, placebo-controlled phase III trial. Lancet. 2008;372(9637):449-56.

http://dx.doi.org/10.1016/S01406736(08)61039-9.

35. Motzer RJ, Escudier B, Oudard S, Hutson TE, Porta C, Bracarda S, et al; RECORD-1 Study Group. Phase 3 trial of everolimus for metastatic renal cell carcinoma: final results and analysis of prognostic factors. Cancer. 2010;116(18):4256-65.

http://dx.doi.org/10.1002/cncr.25219.

36. Pal SK, Jonasch E, Signorovitch JE, Reichmann WM, Li N, Liu Z, et al. Realworld dosing and drug costs with everolimus or axitinib as second targeted therapy for advanced renal cell carcinoma: A retrospective chart review in the U.S. J Med Econ. 2016;11:1-7.

37. Yakes FM, Chen J, Tan J, Yamaguchi K, Shi Y, Yu P, et al. Cabozantinib (XL184), a novel MET and VEGFR2 inhibitor, simultaneously suppresses metastasis, angiogenesis, and tumor growth. Mol Cancer Ther. 2011;10(12):2298-308.

http://dx.doi.org/10.1158/1535-

7163.MCT-11-0264.

38. Motzer RJ, Hutson TE, Glen $\mathrm{H}$, Michaelson MD, Molina A, Eisen T, et al. Lenvatinib, everolimus, and the combination in patients with metastatic renal cell carcinoma: a randomised, phase 2, open-label, multicentre trial. Lancet Oncol. 2015;16:1473-82.

http://dx.doi.org/10.1016/S1470-

2045(15)00290-9.

39. Clinicaltrials.gov. Cabozantinib-smalate or sunitinib malate in treating patients with previously untreated locally advanced or metastatic kidney cancer [Internet]. 2015 [cited 2015 November 22].

Available from:

https://clinicaltrials.gov/show/NCT01835 $\underline{158}$.

40. Clinicaltrials.gov. Nivolumab in combination with sunitinib, pazopanib, or ipilimumab in subjects with metasatic rencal cell carcinoma (RCC)(CheckMate 016) [Internet]. 2015 [cited 2015 November 22]. 
Available from:

https://clinicaltrials.gov/ct2/show/NCT01 472081.

41. Amin A, Pilmack ER, Infante JR, et al. Nivolumab in combination with sunitinib or pazopanib in patients with metastatic renal cell carcinoma. J Clin Oncol 2014;32:5s.

42. Clinicaltrials.gov. Nivolumab combined with ipilumumab versus sunitinib in previoulsy untreated advanced or metastatic renal cell carcinoma (CheckMate 214) [Internet]. 2015 [cited 2015 November 22].

Available from:

https://clinicaltrials.gov/ct2/show/NCTO2 $231749 /$.

43. Clinicaltrials.gov. Autologous Dendritic Cell Immunotherapy Plus Standard
Treatment of Advanced Renal Cell Carcinoma [Internet]. 2015 [cited 2015 November 22]. Available from:

https://clinicaltrials.gov/ct2/show/NCTO1 $\underline{582672}$.

44. Rini B, Stenzi A, Zdroiowy R, Kogan M, Shkolnik S, Oudard S, et al. Results from an open-label, randomized, controlled Phase 3 study investigating IMA901 multipeptide cancer vaccine in patients receiving sunitinib as first line therapy for advanced/metastatic RCC. Presented at the European Cancer Congress, Viena, Austria, September 25-29, 2015.

45. Motzer RJ, Hutson TE, Cella D, Reeves J, Hawkins R, Guo J, et al. Pazopanib versus sunitinib in metastatic renal-cell carcinoma. N Engl J Med. 2013;369:722-31. http://dx.doi.org/10.1056/NEJMoa13039 89. 